\title{
Lauroyl polyoxylglycerides, functionalized coconut oil, enhancing the bioavailability of poorly soluble active substances
}

\author{
Vincent JANNIN \\ Pharmaceutical R\&D, Gattefossé S.A.S., \\ Saint-Priest, 69804, France \\ <vjannin@gattefosse.com>
}

\begin{abstract}
Gelucire ${ }^{\circledR} 44 / 14$, a lauroyl polyoxylglycerides obtained by polyglycolysis of hydrogenated coconut oil with PEG-32, is used to increase the oral bioavailability of poorly-water soluble drugs. It is a solid dispersion composed of a PEG ester fraction under a lamellar phase of $120 \AA$ with a helical conformation and an acylglycerol fraction under a hexagonal packing. This excipient spontaneously evolves to its most stable phase of $120 \AA$ after storage at $25^{\circ} \mathrm{C}$ for 21 hours leading to physically stable formulations. Gelucire ${ }^{\circledR} 44 / 14$ is a hydrophilic system that hydrates and swells in contact with water and forms cubic mesophases before complete erosion/emulsification. It is also lipolyzed by various enzymes such as gastric lipase or carboxyl ester hydrolase. After an in vitro gastrointestinal lipolysis simulation, the main components remaining are mono and diesters of PEG-32. These amphiphilic metabolites can explain the beneficial role of Gelucire ${ }^{\circledR} 44 / 14$ on the solubility of poorly-water soluble drugs such as cinnarizine even after partial lipolysis of the lipid-based system. Finally that excipient can also increase the bioavailability of active substances by interacting with enterocyte-based proteins like P-glycoprotein or cytochromes P450.
\end{abstract}

Key words: coconut oil, crystalline structure, emulsification, lauroyl polyoxylglycerides, lipolysis, poorly-water soluble drug

cerols) and PEG-32. It is composed of a defined admixture of C8-C18 mono-, di- and triacylglycerols $(20 \% \mathrm{w} / \mathrm{w})$, PEG-32 mono- and diesters and free PEG-32 $(80 \% \mathrm{w} / \mathrm{w})$. The main fatty acid present is lauric acid which accounts for $45 \%$ on average of the total fatty acids [5-7]. Gelucire $^{\circledR} 44 / 14$ has been widely used and characterized during the last five years in order to increase the solubility and bioavailability of many drugs: carbamazepine [8], glibenclamide [9], antiviral agent PG301026 [10], piroxicam $[11,12]$, propranolol $[13,14]$, flurbiprofen [15], aceclofenac [16], carvedilol [17], griseofulvin [18], spironolactone [19], and cinnarizine [11].

The aim of this paper is to present the physical and biopharmaceutical characterizations needed to develop a successful formulation with Gelucire $^{\circledR} 44 / 14$.

\section{Physical characterization}

As Gelucire ${ }^{\circledR} 44 / 14$ is a semi-solid crystalline excipient, formulators should characterize the structure of the mixture containing this lipidbased vehicle and the drug substance to ascertain that their formulation is in its most stable form and retains its self-emulsifying properties. In this chapter, the main physical characterization tests needed are presented firstly on the raw material and secondly with two model drug substances.

\section{Thermal analysis}

Figure 1 shows the thermogram of the first melting of a Gelucire ${ }^{\circledR} 44 / 14$ sample recorded with a Differential Scanning Calorimeter (Pyris Diamond, Perkin-Elmer, USA) calibrated with benzoic acid $\left(T_{m}=122.4{ }^{\circ} \mathrm{C}\right)$ and indium $\left(\mathrm{T}_{\mathrm{m}}=156.6^{\circ} \mathrm{C}, \Delta \mathrm{H}_{\mathrm{m}}=26.6 \mathrm{~J} / \mathrm{g}\right.$ ). The thermal analysis was carried out between -20 and $120^{\circ} \mathrm{C}$ at a heating rate of $3{ }^{\circ} \mathrm{C} / \mathrm{min}$ on a $10 \mathrm{mg}$ sample. Gelucire ${ }^{\circledR} 44 / 14$ presents a broad endotherm ranging from 10 to $45^{\circ} \mathrm{C}$ with an onset melting temperature of $38.2^{\circ} \mathrm{C}$ and a peak melting temperature of $43.2^{\circ} \mathrm{C}$. This thermal behaviour can be explained by the composition of the excipient, a mixture of acylglycerols and PEG esters. The Differential Scanning Calorimetry (DSC) analyses of these two fractions separately (figure 1) show that the acylglycerol fraction melts first (representing the first two endothermic events), and then the PEG ester and free PEG fraction melts last (representing the last and main endothermic event).

\section{Crystalline structure}

The combined use of X-Ray Diffraction (XRD) and DSC allows the detection of all polymorphs formed after various thermal treatments ranging from quenching into liquid nitrogen to slow crystallization. XRD allows the study of 


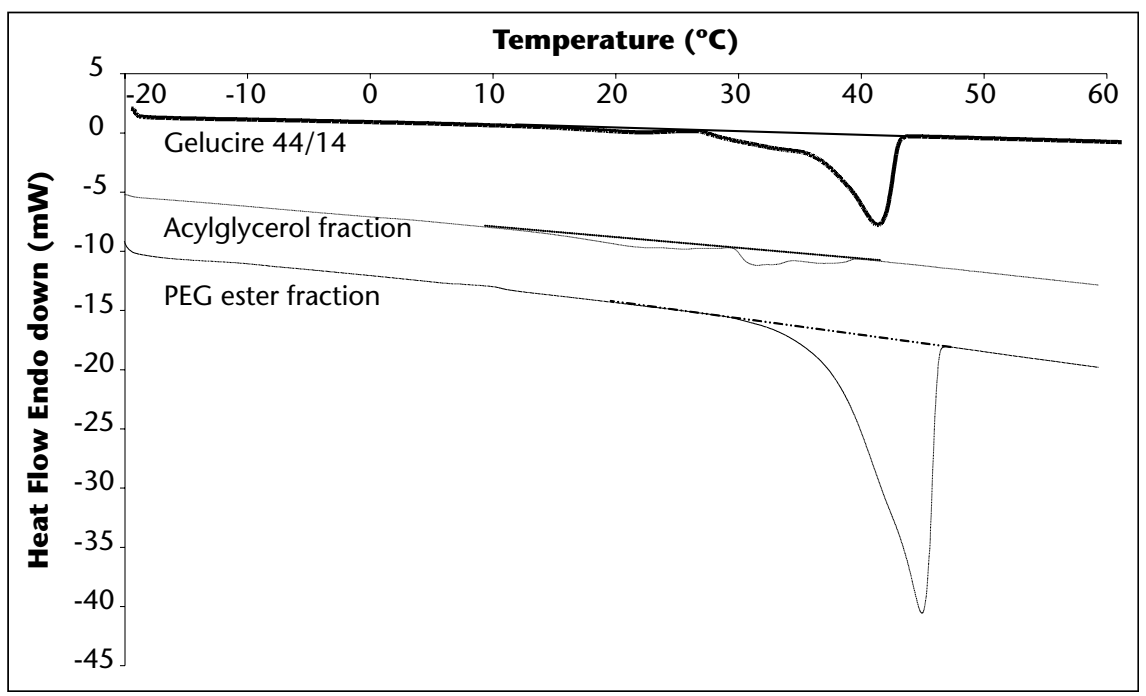

Figure 1. Thermograms of the first melting of Gelucire ${ }^{\circledast} 44 / 14$ (solid line), the acylglycerol fraction of Celucire ${ }^{\circledR}$ $44 / 14$ (dotted line), and the PEG ester fraction of Gelucire ${ }^{\circledR} 44 / 14$ (dashed dot dot line) at a heating rate of $3{ }^{\circ} \mathrm{C} / \mathrm{min}$.

the structure and the polymorphism of lipidbased compound. Wide-Angle X-ray Scattering (WAXS) region corresponds to short reticular distances between hydrocarbon chains while Small-Angle $X$-ray Scattering (SAXS) domain corresponds to long spacing. DSC, by temperature and enthalpy of phasetransition measurement, shows energy transfers that occur during the heating or cooling of the sample. By combining these two techniques, one can link structural changes to phase transitions.

Gelucire $^{\circledR} 44 / 14$ is crystallized in lamellar phases with the PEG chains under a helical conformation. This crystalline structure has already been reported for another polyoxylglycerides containing the same ethylene oxide unit: Gelucire ${ }^{\circledR}$ 50/13 [20]. SAXS analysis of the untreated sample shows a lamellar phase of $120 \AA$ (figure 2). No signal of the acylglycerol fraction was detected. Various polymorphs with shorter lamellar phases such as 90, 94, 99 or $105 \AA$ were detected when the product is melted and crystallized with different crystallization rates. Shorter structures were due to the more or less important tilt of the PEC chains. However during the heating of these freshly crystallized samples, we observed a progressive phase transition from the tilted lamellar phases to the most stable phase of $120 \AA$ A. Figure 3 shows that the sample evolves by itself to its most stable form after storage of 21 hours at $25{ }^{\circ} \mathrm{C}$. This phenomenon was confirmed with WAXS analysis of samples crystallized slowly at $0.1{ }^{\circ} \mathrm{C} / \mathrm{min}$ or by quenching into liquid nitrogen (figure 4).
WAXS measurement also allowed detecting acylglycerols under a hexagonal lattice.

This study demonstrates that Gelucire ${ }^{\circledR}$ 44/14 evolves to the most stable form (lamellar phase of $120 \AA$ ) whatever the crystallization rate applied during the formulation process if left 21 hours at $25^{\circ} \mathrm{C}$.

\section{Hydration and emulsification performance}

Naproxen and sodium naproxen were chosen as model drugs to evaluate the impact of drug polarity on the wettability and emulsification performance of Gelucire ${ }^{\circledR} 44 / 14$. Model drugs were added at $10 \% \mathrm{w} / \mathrm{w}$ to the molten excipient under stirring. The mixture obtained with Gelucire $^{\circledR} 44 / 14$ was either a solid solution in the case of naproxen or a solid dispersion with sodium naproxen as detected by DSC and XRD [21]. Gelucire ${ }^{\circledR} 44 / 14$ and these two mixtures were used to form films with an Automatic Film Applicator (Sheen-1137, height $=2 \mathrm{~mm}$, spreading rate $=0.05 \mathrm{~ms}^{-1}$ ). Gelucire ${ }^{\circledR}$ $44 / 14$ film shows an irregular surface, with slopes and localized folds [21]. The inclusion of naproxen results in a smoother surface. The inclusion of sodium naproxen gives a surface which is more broken; numerous edges and deep cavities of $50 \mu \mathrm{m}$ of diameter can be observed. This film crystallizes quicker than the other ones, giving a more porous structure. In this case the drug acts as a nucleation enhancer where newly-formed crystals diffuse toward existing drug crystals creating cavities in the film. The surface of the film containing sodium naproxen is also affected by the morphology of the drug crystals as this substance is not soluble in Gelucire ${ }^{\circledR} 44 / 14$ [22].

Wettability of these films by water was characterized by goniometry (G1 Krüss goniometer, Krüss $\mathrm{GmbH}$, Germany). Initial contact angles are similar whatever the drug used and are identical to those obtained with Gelucire ${ }^{\circledR}$ $\left(53.1 \pm 4.9^{\circ}, 57.9 \pm 5.6^{\circ}\right.$, and $64.8 \pm 7.8^{\circ}$ for Gelucire $^{\circledR} 44 / 14$, the mixture containing naproxen, and the mixture with sodium naproxen, respectively). This shows that Gelucire $^{\circledR} 44 / 14$ hydrophilicity dominates the polarity differences of the two drug models as all initial contact angles were below $65^{\circ}$, implying a hydrophilic surface which is required for rapid emulsification in a lipid-based self emulsifying system. However the contact angle at the equilibrium was statistically higher for the mixture containing naproxen due to the hydrophobicity of the drug. On the other hand, the rate of spreading of the water drop (i.e. wettability) is similar for Gelucire ${ }^{\circledR}$ $44 / 14$ alone and the mixture with naproxen $\left(-1.68 \pm 0.5^{\circ} / \mathrm{s}\right.$, and $-1.86 \pm 0.5^{\circ} / \mathrm{s}$, respectively), but dramatically decreased for the mixture with sodium naproxen due to the broken surface of the sample $(-2.89 \pm 0.5 \%$ s $)$ [21]

Figure 5 presents the variation of viscosity and refraction index of Gelucire ${ }^{\circledR} 44 / 14$ during the discrete addition of water at $45{ }^{\circ} \mathrm{C}$ under stirring (100 rpm). The addition of up to $13 \%$ $\mathrm{w} / \mathrm{w}$ of water into the molten Gelucire ${ }^{\circledR}$ $44 / 14$ leads to a liquid solution with the same viscosity as the excipient itself (below $100 \mathrm{mPa} . \mathrm{s})$. This amount of water is needed to completely hydrate the ethylene oxide units in the PEG ester and free PEG fraction [23]. The system slowly becomes a transparent gel with the addition of 13 to $43 \% \mathrm{w} / \mathrm{w}$ of water, the viscosity steadily increasing from 0.1 to 1 Pa.s. Then a high viscosity gel is formed between 43 and $61 \% \mathrm{w} / \mathrm{w}$ of water. The increase of viscosity measured up to 7 Pa.s is due to the formation of cubic mesophases. This gel slowly erodes and emulsifies with the addition of increasing amounts of water to become a turbid gel with low viscosity (61 to $75 \% \mathrm{w} / \mathrm{w}$ of water), then a turbid liquid system (75 to $90 \% \mathrm{w} / \mathrm{w}$ of water) and finally a translucent liquid system for high aqueous dilutions. This last system is characterized as a microemulsion with a particle size distribution of $80 \mathrm{~nm}$ (measured with a photon correlation spectrophotometer, PSS Nicomp, USA).

These studies demonstrate that Gelucire ${ }^{\circledR}$ 44/14 hydrophilicity dominates the polarity of the model drugs and favour the hydration of the lipid-based systems leading to a cubic phase system that erodes/emulsifies with the hydrodynamic of the aqueous environment. 


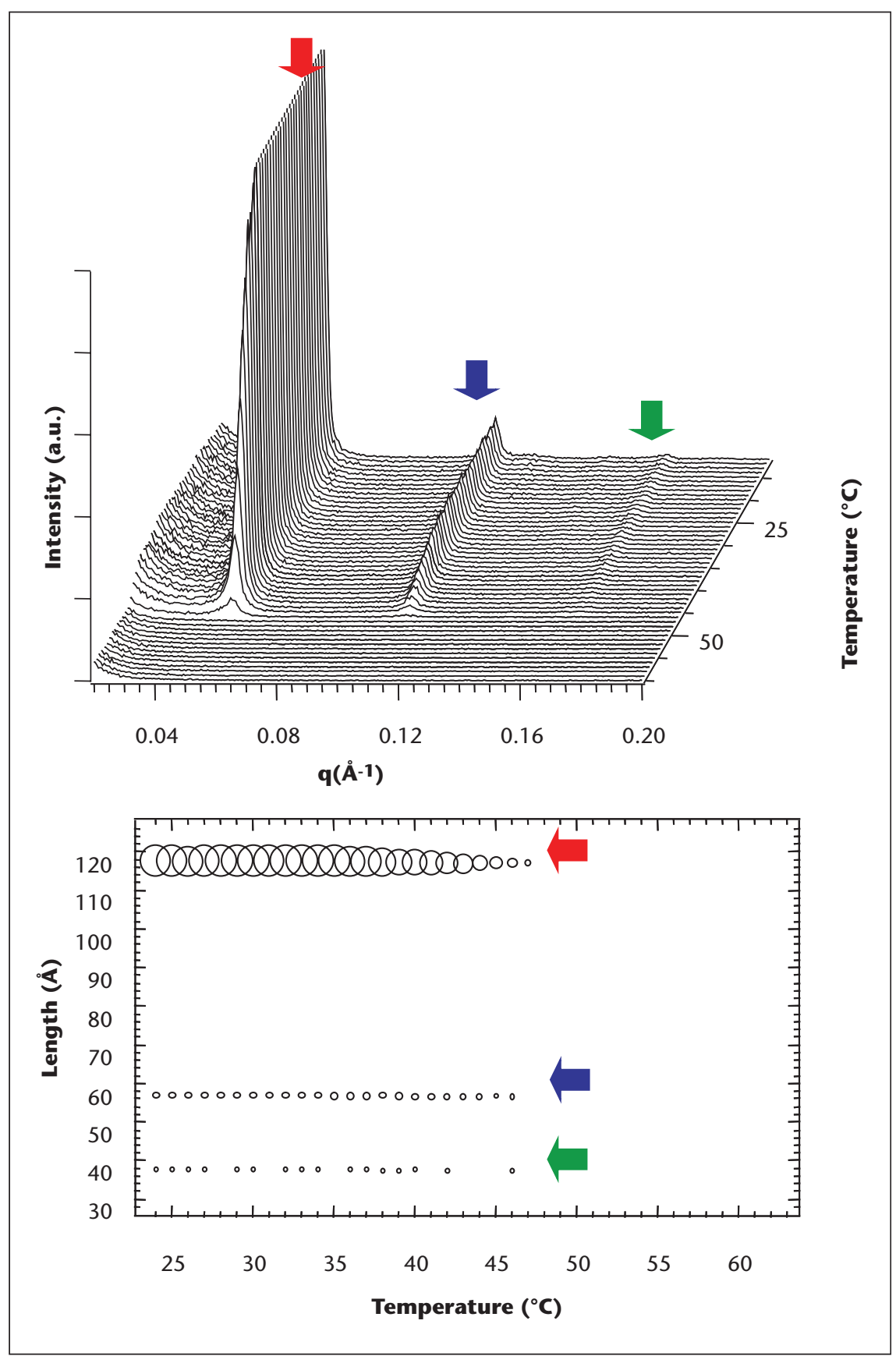

Figure 2. 3D evolution of SAXS patterns versus scattering vector $q\left(\AA^{-1}\right)$ upon the first heating of a Gelucire ${ }^{\circledast} 44 / 14$ sample (top). The lower part of the figure shows the evolution of the X-Ray Diffraction peak positions $d(\AA)$ as a function of temperature, where $d(\AA)=\left(2^{*} p i\right) / q\left(\AA^{-1}\right)$.

\section{Biopharmaceutical characterization}

In the previous chapter the ability of Gelucire ${ }^{\circledR} 44 / 14$ to evolve into a stable crystalline form and to self-emulsify in contact with water in vitro was presented. However, this excipient is a lipid-based system, containing
Lipolysis

The lipolysis of Gelucire ${ }^{\circledR} 44 / 14$ and its fractions was evaluated by measuring the release of free fatty acids (FFAs) with a pH-stat apparatus (718 STAT Titrino, Metrohm, Switzerland) adjusted to a constant end-point value [24]. An emulsion of $500 \mathrm{mg}$ Gelucire $^{\circledR} 44 / 14$ in $15.0 \mathrm{~mL}$ of an assay solution $(\mathrm{NaCl} 150 \mathrm{mM}$; $\mathrm{NaTDC} 4 \mathrm{mM} ; \mathrm{CaCl}_{2} 1.4 \mathrm{mM}$; Tris- $\mathrm{HCl} 1 \mathrm{mM}$ ) was mechanically stirred $(450 \mathrm{rpm})$ in a temperature-controlled reaction vessel at $37^{\circ} \mathrm{C}$. Before adding enzymatic solution, we waited for 5 min until the gel phase disappeared and a translucent medium is obtained. The $\mathrm{pH}$ was kept constant using an automated burette to titrate FFAs with a $0.1 \mathrm{M} \mathrm{NaOH}$ solution. Activities were expressed in international units: $1 \mathrm{U}$ corresponds to $1 \mu \mathrm{mol}$ of FFAs released per minute. Specific activities were expressed as U per mg of pure enzyme.

Table 1 presents the specific activities of four lipases on Gelucire ${ }^{\circledR} 44 / 14$ and its components: acylglycerol fraction and PEG fraction [7]. Human Pancreatic Lipase (HPL), the main lipase involved in the digestion of dietary triacylglycerols, does not show any significant activity on Gelucire ${ }^{\circledR} 44 / 14(2 \pm 2 \mathrm{U} / \mathrm{mg})$ nor on either of its fractions. Other pancreatic lipases such as Human Pancreatic Lipase-Related Protein 2 (HPLRP2) show low activity on Gelucire ${ }^{\circledR}$ 44/14 (12 $\pm 1 \mathrm{U} / \mathrm{mg})$ although the highest activity of HPLRP2 is that observed on the acylglycerol fraction $(333 \pm 0 \mathrm{U} / \mathrm{mg})$. In addition, this enzyme shows low activity on the PEG ester fraction. Carboxyl Ester Hydrolase (CEH) shows high activity on Gelucire ${ }^{\circledR} 44 / 14$ $(96 \pm 2 \mathrm{U} / \mathrm{mg}$ ), and the highest activity of $\mathrm{CEH}$ is that recorded on the PEG ester fraction $(50 \pm 12 \mathrm{U} / \mathrm{mg})$. The highest activity of all the enzymes tested is that of Dog Gastric Lipase (DGL) on Gelucire ${ }^{\circledR} 44 / 14(108 \pm 10 \mathrm{U} / \mathrm{mg})$, although DGL shows low activity on the PEG ester fraction.

Gastric lipase probably plays an essential role in the in vivo digestion of Gelucire ${ }^{\circledR} 44 / 14$ although it is less abundant than pancreatic lipase in the human digestive system. In addition, the main pancreatic enzyme involved in the intestinal digestion step of Gelucire ${ }^{\circledR} 44 / 14$ is probably $\mathrm{CEH}$.

\section{Impact of lipolysis on the solubilising performance of Gelucire ${ }^{\circledast} 44 / 14$}

The in vitro gastrointestinal lipolysis of Gelucire $^{\circledR} 44 / 14$ was then investigated to understand which compounds are, after digestion, responsible for keeping poorly watersoluble drugs in solution [11]. Experimental conditions were adapted from in vivo data recorded at $50 \%$ gastric emptying of test meals, both in the stomach and in the duodenum, and 


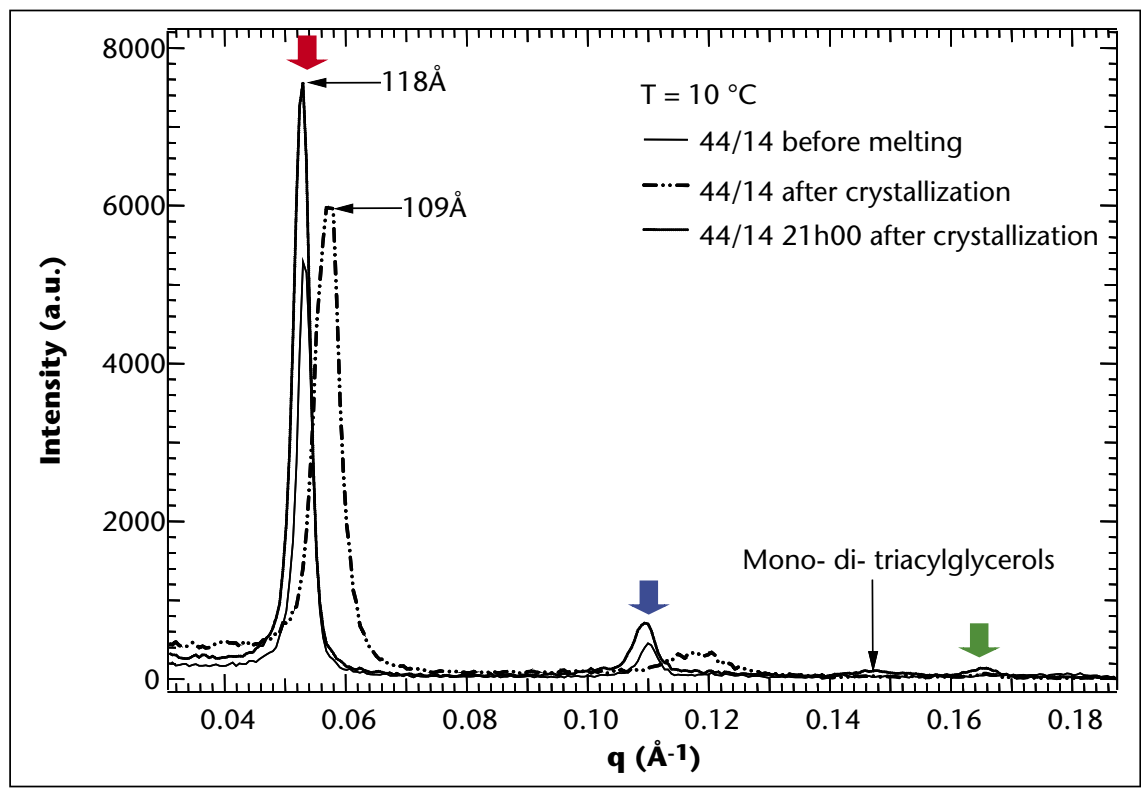

Figure 3. Comparison of SAXS patterns versus scattering vector $q\left(\AA^{-1}\right)$ of Gelucire ${ }^{\circledR} 44 / 14$ samples measured at $10^{\circ} \mathrm{C}$ before melting (solid line), after crystallization (dashed dot dot line), and after storage at $25^{\circ} \mathrm{C}$ for 21 hours (dotted line).

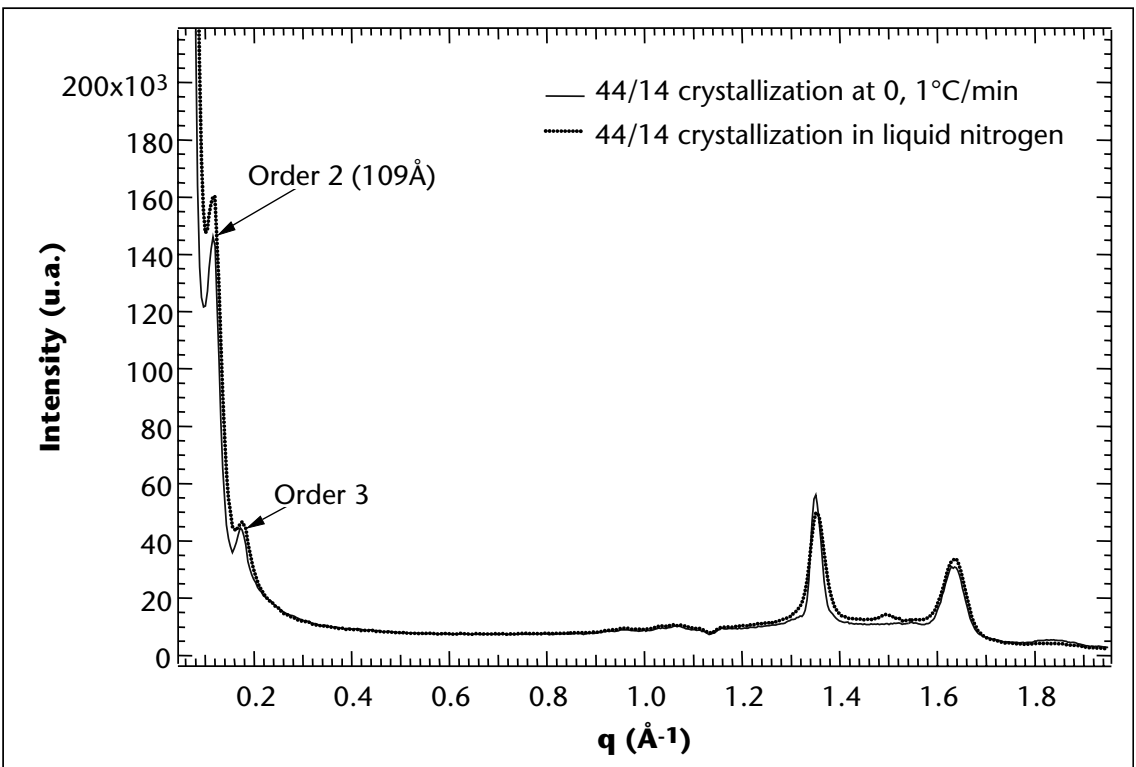

Figure 4. Comparison of WAXS patterns versus scattering vector $q\left(\AA^{-1}\right)$ of two Gelucire ${ }^{\circledR} 44 / 14$ samples crystallized at either $0.1{ }^{\circ} \mathrm{C} / \mathrm{min}$ (solid line) or by quenching in liquid nitrogen (dotted line) and stored thereafter at $25^{\circ} \mathrm{C}$ for 21 hours.

enzymatic solutions were prepared according to in vivo secretions of lipases during a meal [25]. Experiments were performed over a period of 90 minutes to simulate the gastrointestinal digestion of lipids. An emulsion of Gelucire ${ }^{\circledR} 44 / 14$ with either piroxicam or cinnarizine in the assay solution was mechanically stirred in a temperature-controlled reaction vessel at $37^{\circ} \mathrm{C}$. Then a freshly prepared gastric enzymatic solution (rDCL) was added to the reaction vessel and the $\mathrm{pH}$ was kept constant at 5.5 during 30 min (gastric step of lipolysis), via an automated titration of FFAs with $0.1 \mathrm{M}$ $\mathrm{NaOH}$ using a pH-stat device. After the gastric step, a freshly prepared pancreatic enzymatic solution was added to the mixture (dilution by 1.7-fold) and the $\mathrm{pH}$ was shifted to 6.25 and kept constant for $60 \mathrm{~min}$. At different time points, samples were taken to assay each component of Gelucire ${ }^{\circledR} 44 / 14$ and also the percentage of drug dissolved in the aqueous phase.

During the gastrointestinal lipolysis of Gelucire $^{\circledast} 44 / 14$, monoacylglycerols and PEG esters are the largest compounds present at the end of gastric phase, and PEG mono and diesters are the largest compounds after the duodenal phase.

Solutions of Gelucire ${ }^{\circledast} 44 / 14$ with either piroxicam or cinnarizine were formulated to evaluate the precipitation of these active substances during the gastrointestinal lipolysis of the excipient [11]. The precipitation of piroxicam is mainly due to the gastric lipolysis of Gelucire ${ }^{\circledast}$ $44 / 14$ nevertheless the aqueous solubility of this drug is increased 4-fold due to the metabolites of the lipid-based excipient. With respect to the formulation of cinnarizine with Gelucire $^{\circledR} 44 / 14$, drug precipitation is only associated with the dilution of the gastric medium by the pancreatic juice until it reaches the composition of the duodenal medium. However, at the end of simulation of the gastrointestinal lipolysis, the aqueous solubility of cinnarizine formulated with Gelucire ${ }^{\circledR} 44 / 14$ is increased 132-fold when compared with its aqueous solubility without excipient. This study highlights the importance of gastrointestinal lipolysis and the associated phenomena such as the dilution of chyme by biliary and pancreatic secretions in vivo, on the solubilisation of poorly water-soluble drugs formulated with Gelucire ${ }^{\circledR} 44 / 14$ [11].

\section{Interaction with enterocyte-based proteins}

The absorption and bioavailability of active substances can be limited by enterocyte-based proteins such as P-glycoprotein (P-gp), an efflux protein that transports the drug out of the cell, or by cytochrome P450 enzyme that transform active substances into metabolites. In both cases the access of the drug to systemic circulation is limited and its bioavailability reduced.

Celucire $^{\circledR} 44 / 14$ demonstrated its inhibitory effect on efflux proteins such as P-gp both in vitro diffusion chambers [26] and with Caco2 cells monolayer $[27,28]$. The inhibition of the efflux of Rhodamine 123 in diffusion chambers is observed for concentrations of Gelucire ${ }^{\circledR}$ $44 / 14$ ranging from 1.0 to $10.0 \% \mathrm{v} / \mathrm{v}$. These concentrations are higher than the critical micellar concentration of the excipient $(0.01 \% \mathrm{v} / \mathrm{v})$ suggesting that the drug should be included into micelles in order to increase its absorption [26]. Recently it has been proposed that Gelucire ${ }^{\circledR} 44 / 14$ specifically inhibits P-gp and not Breast Cancer Resistance Protein (BCRP) another efflux protein [29]. 


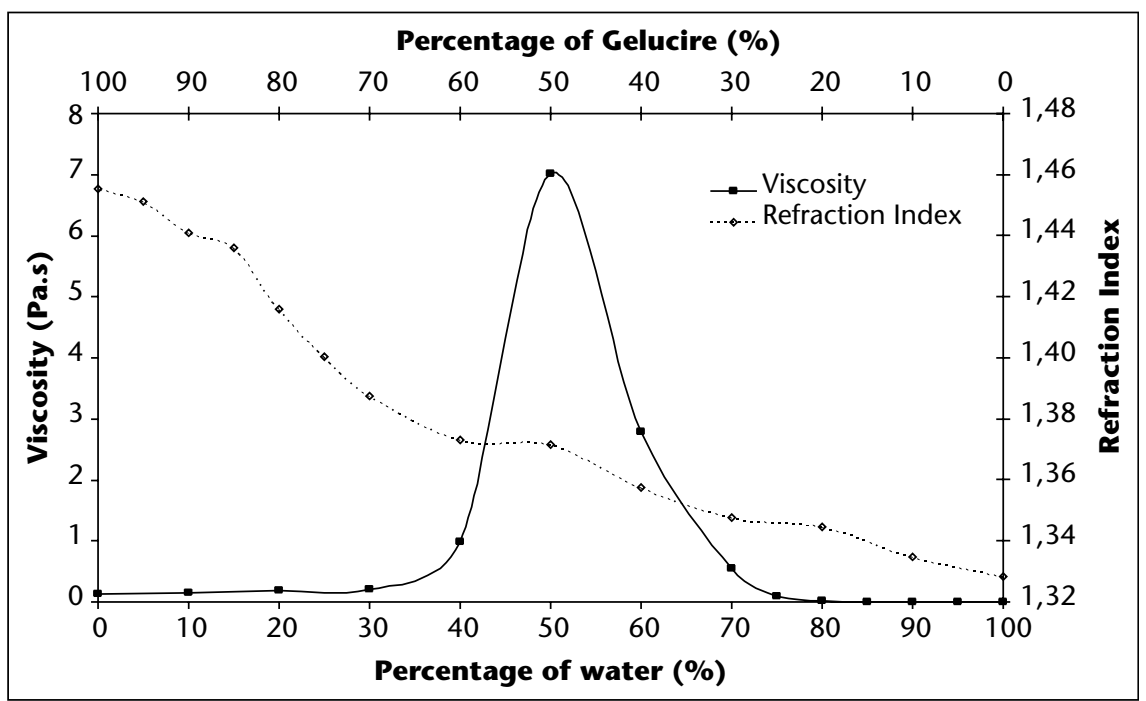

Figure 5. Evolution of the refraction index and viscosity during the addition of water to Gelucire ${ }^{\circledR} 44 / 14$ at $45^{\circ} \mathrm{C}$.

Table 1. Specific activities of Human Pancreatic Lipase (HPL), Human Pancreatic Lipase Related Protein 2 (HPLRP2), Carboxyl Ester Hydrolase (CEH), and Dog Gastric Lipase (DCL) on Gelucire ${ }^{\circledast} 44 / 14$ and its two fractions: acylglycerols and PEG esters. Specific activities are expressed in $\mathrm{U} / \mathrm{mg}$ as mean \pm standard deviation $(n=2)$.

\begin{tabular}{|lccc|}
\hline Enzymes & \multicolumn{2}{l|}{ Specific activity (U/mg) } \\
\cline { 2 - 4 } & Celucire $^{\circledR} \mathbf{4 4 / 1 4}$ & Acylglycerols fraction & $\begin{array}{l}\text { PEC esters } \\
\text { fraction }\end{array}$ \\
\hline rHPL & $2 \pm 2$ & $20 \pm 0$ & $6 \pm 0$ \\
rHPLRP2 & $12 \pm 1$ & $333 \pm 0$ & $5 \pm 2$ \\
CEH & $96 \pm 2$ & $163 \pm 7$ & $50 \pm 12$ \\
DGL & $108 \pm 10$ & $106 \pm 3$ & $21 \pm 6$ \\
\hline
\end{tabular}

Gelucire $^{\circledR} 44 / 14$ has also shown its ability to inhibit the metabolism of active substances by cytochrome P450 on human liver microsomes $[28,30]$.

Acknowledgements. We gratefully thank all our academic partners who help us characterizing Gelucire ${ }^{\circledR} 44 / 14$ over the past five years: Prof. Odile Chambin (Pharmaceutical Technology Group, EMMA Team, EA 581, Faculté de Pharmacie, Dijon, France), Dr. Frédéric Carrière and Dr. Sylvie Fernandez (Laboratoire d'Enzymologie Interfaciale et de Physiologie de la Lipolyse, CNRS UPR 9025, Marseille, France), Dr. Jean-Blaise Brubach and late Dr. Michel Ollivon (Laboratoire de Physicochimie des Systèmes Polyphasés, UMR 8612, Faculté de Pharmacie, Châtenay Malabry, France).

\section{REFERENCES}

1. Gursoy RN, Benita S. Self-emulsifying drug delivery systems (SEDDS) for improved oral delivery of lipophilic drugs. Biomed Pharmacother $2004 ; 58: 173-82$.
8. Barakat NS, Elanazi FK, Almurshedi AS. The influence of various amphiphilic excipients on the physicochemical properties of carbamazepine-loaded microparticles. I Microencapsul $2008 ; 4$ : 1-12.

9. Deepti DH, Madan A. Solid dispersion adsorbates for enhancement of dissolution rates of drugs. PDA J Pharm Sci Technol 2007 ; 61 : 97-101.

10. He Y, Johnson JL, Yalkowsky SH. Oral formulation of a novel antiviral agent, PG301029, in a mixture of gelucire 44/14 and DMA (2:1, wt/ wt). AAPS Pharm Sci Tech $2005 ; 6:$ E1-5.

11. Fernandez $S$, Chevrier $S$, Ritter $N$, Mahler $B$, Demarne $F$, Carrière $F$, Jannin V. In vitro gastrointestinal lipolysis of four formulations of piroxicam and cinnarizine with the self emulsifying excipients Labrasol $\circledast$ and Gelucire $₫ 44 / 14$. Pharm Res 2009; 26 : 1901-11.

12. Karatas A, Yuksel N, Baykara T. Improved solubility and dissolution rate of piroxicam using gelucire 44/14 and labrasol. Farmaco 2005; $60: 777-82$.

13. Mehuys E, Vervaet C, Gielen I, Van BH, Remon JP. In vitro and in vivo evaluation of a matrixin-cylinder system for sustained drug delivery. / Control Release 2004 ; 96 : 261-71.

14. Mehuys E, Remon JP, Korst A, et al. Human bioavailability of propranolol from a matrixin-cylinder system with a HPMC-Gelucire core. J Control Release 2005 ; 107 : 523-36.

15. Soliman MS, Khan MA. Preparation and in vitro characterization of a semi-solid dispersion of flurbiprofen with Gelucire 44/14 and Labrasol. Pharmazie $2005 ; 60$ : 288-93.

16. Tran $\Pi$, Tran PH, Lee BJ. Dissolutionmodulating mechanism of alkalizers and polymers in a nanoemulsifying solid dispersion containing ionizable and poorly water-soluble drug. Eur J Pharm Biopharm 2009 ; 72 : 83-90.

17. Wei L, Li J, Guo L, et al. Investigations of a novel self-emulsifying osmotic pump tablet containing carvedilol. Drug Dev Ind Pharm 2007 ; 33 : 990-8.

18. Yang D, Kulkarni R, Behme RJ, Kotiyan PN. Effect of the melt granulation technique on the dissolution characteristics of griseofulvin. Int / Pharm 2007 ; 329 : 72-80.

19. Yassin AE, Alanazi FK, El-Badry M, Alsarra IA, Barakat NS, Alanazi FK. Preparation and characterization of spironolactone-loaded gelucire microparticles using spray-drying technique. Drug Dev Ind Pharm 2009 ; 35 : 297-304.

20. Brubach JB, Ollivon $M$, Jannin $V$, et al. Structural and thermal characterization of mono- and diacyl polyoxyethylene glycol by infrared spectroscopy and X-ray diffraction coupled to differential calorimetry. J Phys Chem B 2004 ; 108 : 17721 -9. 
21. Chambin O, Karbowiak T, Djebili L, et al. Influence of drug polarity upon the solid-state structure and release properties of selfemulsifying drug delivery systems in relation with water affinity. Coll Surf B $2009 ; 71$ : 73-8.

22. Khan N, Craig DQM. The influence of drug incorporation on the structure and release properties of solid dispersions in lipid matrices. J Control Release 2003 ; 93 : 355-68.

23. Svensson A, Neves C, Cabane B. Hydration of an amphiphilic excipient, Gelucire 44/14. Int J Pharm 2004 ; 281 : 107-18.

24. Fernandez S, Jannin V, Rodier JD, Ritter N, Mahler B, Carrière F. Comparative study of digestive lipases performance on the self emulsifying excipient Labrasol囚, medium chain glycerides and PEG esters. Biochim Biophys Acta 2007; 1771: $633-40$.
25. Carriere F, Renou C, Lopez V, et al. The specific activities of human digestive lipases measured from the in vivo and in vitro lipolysis of test meals. Gastroenterology $2000 ; 119$ : 949-60.

26. Lin $Y$, Shen Q, Katsumi $H$, et al. Effects of Labrasol and Other Pharmaceutical Excipients on the Intestinal Transport and Absorption of Rhodamine123, a P-Glycoprotein Substrate, in Rats. Biol Pharm Bull $2007 ; 30$ : 1301-7.

27. Sachs-Barrable K, Thamboo A, Lee SD, Wasan KM. Lipid Excipients Peceol and Gelucire 44/14 decrease P-glycoprotein mediated efflux of Rhodamine 123 partially due to modifying Pglycoprotein protein expression within Caco-2 Cells. J Pharm Pharm Sci 2007 ; 10 : 319-31.

28. Benameur $\mathbf{H}$. Liquid and semi-solid formulations for enhancing oral absorption. Bull Tech Gattefossé 2006 ; 99 : 63-75.
29. Yamagata $T$, Kusuhara $H$, Morishita $M$, Takayama K, Benameur H, Sugiyama Y. Effect of excipients on breast cancer resistance protein substrate uptake activity. / Control Release 2007 ; 124 : 1-5.

30. Ren S, Park M], Kim A, Lee B]. In vitro metabolic stability of moisture-sensitive rabeprazole in human liver microsomes and its modulation by pharmaceutical excipients. Arch Pharm Res $2008 ; 31: 406-13$. 